niet te pretenderen hebben, met desen bedinge, soo wanneer eenige vaartuijgen onser ingesetenen op de custe van Seijlon onder 's Comps gebiet staen quamen te blijven, soo sullen U. E. insgelijx deselve vrij kennen, sulx is bij den Neijck toegestaan, dienvolgende zich na 't bovenstaande gelieft te voegen.

\title{
CCXXXVII. FORMOSA.
}

4 Mei $\left.1659 .{ }^{1}\right)$

Het stelsel, verschillende dorpen op Formosa tot één te vereenigen, werd ook in de nadagen van de Compagnie's heerschappij over dit eiland voortgezet, op verzoek der bevolking, maar met volkomen instemming der Nederlandsche autoriteiten. Deze moesten daarvoor de toestemming geven. (Grothe, Archief, IV, bldz. 33, enz.).

Provisioneell contract tusschen d'ouste van Teijvourangh ende Dorko ${ }^{2}$ ) opt goetvinden ende toestemmen van Haer $E_{d}{ }^{e} d^{\prime} E$. Heer Gouverneur ende Raden van Formosa gedaen en besloten bij de Nederlantsche opperhooffden in Mattou ${ }^{3}$ ) resederende.

Den $30^{\circ}$ Aprill $A^{\circ} 1659$ verscheenen voor mij ondergeschreven en d'getuijgen naergenoemt drie Teijvorangers met namen Sakolou ende Keramell Calangh Thamill ende Lavateij Toussell, verclarende zij deposanten affgesonden zijn van beijde de capiteijns hares dorps met namen Doulinghs Lavaos en Swak T. Dellio ende van beijcle Caps Dourap Lipangh ende Ourine Hamill, als ook haer gantsche dorpsvolcks, om uijt aller gemeenen name te spreeken met d'oussten en d'gemeijnte van Dorko en haer vrijwillige genegentheijt aen desellve te openbaren van gemelte haer dorp Teijvoijrangh te verlaten en met alle man, vrou en kinderen, met alles wat zij hadden uijt het geberghde op te breeken en sigh ter neder te slaen in Touvavullbulangh bij d'Mattauwers, Likogh bij de Dorkorsche ende Varevarcan bij de Flipourangeren genoemdt, zijnde een plaetse gelegen ontrent een uijr oosstwaerts op van Dorko reght op d' allderkorste passagie

1) Uit het Contractbock.

2) Zie over deze dorpen Grothe, Archief, IV, bldz. 69, v.

3) „Het.... dorp Mattouw is gelegen midden in de revieren, en als een rẹchte Mesopotamiën..." (Grothe, Archief, bldz. 196). 
van Baclovan naer Tilaossen met aensoek aen d'Dorkoers voornoent van alldaer neffens haer te willen comen woonen tot versterckinge en vergrootinge van $t$ nieuw te makende dorp alldaer, waer op zij, affgesondenen voornoemt, waren te rade geworden om geseijcle hare genegentheijt tot verplaetsinge oock te comen openbaren aen mij allhier in Mattou.

Op welck haerluijcler voorstell partijculierlijck aen mij gedaen, dan van stonden aen d'ondergeschreven Duijtsche ${ }^{1}$ ) schoollm $^{r}$ bij mij ontboden hebbe on $d^{\circ}$ voorslag voor haerluijden als getuijgen te doen horen, gelijck geschiet ende dan verders d'ousten neffens den schoolm $^{\mathrm{r}}$ van Dorko daer op te ontbieden om uijt haerluijclen ook te vernemen off de zake ook zodanigh lagh als ons desellve allhier wiert aengebraght.

Waerop als de Dorkanners ook allhier waren aengecomen, zoo is de zake bij gevolgh ende nae onderlingh gespreck eijndelijck zoo verre gebraght dat de bij de Teijvourangers op onzen gedanen voorslagh is in bedenckinge genomen om met de oudsten, bijlopers en $t$ gemene volk hares dorps naerder t'overwegen ende sigh daer op te beraden of ft niet beter en ware dat sigh met gemeender handt ter neder sloegen in het dorp Dorko selffs, om redenen dat sulx buijten twijffell allderaengenaemst soude wesen voor sijne $\mathrm{Ed}^{t}$ den Heer Gouverneur, d'minste moeijte voor die van Dorko ende dat haerluijclen sellve zoo heel veell in d'aen te wenden moeijte van verplaetsinge niet en scheen te verscheelen, off soo sulx niet vallen en willde of $\mathrm{zij}$ dan ook fast stonden om sigh te sijnen tijt op d'voornoemcle plaetse ter neder te slaen, bij alldien de Dorkanders die aennamen dit sellve naerder met haer gantsche dorpsvolck te communiceren ende haerlieden gemeen andtwoordt daerop in te brengen, sigh alldaer ter plaetse bij haerlieden willde vervoegen.

Ende zijn beijde de partijen allsoo gescheijden op reces met belooffte van tegens den volgenden Sondagh, die wesen soude den $4^{\mathrm{e}}$ Maij, sigh allhier weder in Mattou te laten vinden ende dat met volnaght en finale uijtspraeck ijder van haerluijcler principalen respectijff op de poincten voornoemt, $t$ welk dan op heden in dier voegen is geschiet.

Dat beijde de Feijvourangers en de Dorkanders verklaren vrijwilligh ende volcomentlijck genegen te zijn, elck hare tot nogh toe

1) Nederlandschẹ. 
bewoonde dorpen ende woonplaetsen te verlaten ende sigh alsoo gesamentlijck ter neder te slaen op Vare Aug(?), Likog offte Tavullbelangh voornoemt, belovende malcanderen volcomene gemeenschap van jaght en jaeghvellden, bamboes ende houdtbosschen en voorts alles wadt dies meer is, niet anders dan off $\mathrm{zij}$ waren niet alleen één dorpsvolk maer één lighaem, selffs doende dese verklaring ende verzeekeringh daerbij, nae dat ijder wederzijts dit aenstaende zuijdermousson zijn gewoonlijck zaijvellden nogh eens ende data voor $t$ laeste sall besaeijt hebben, dat als dan ter geseijder tijt en plaetse preparatie van nieuwe vellden tegens eerstvolgende noorder mousson sullen beginnen te maeken, onder vaste en onverbreekelijcke belofften van met vrouwen, kinderen, huijs en huijsraedt, padje en reijs ende wadt dies meer is, tot varkens ende rijsblocken incluijs, geheel ende all over te sullen zijn tegen $t$ aenstaende nieuwe jaer 1660 .

Ende dit alles ter presentie en inwilliginge der ousten van Mattou op $t$ goedtvinden ende toestemminge van sijn Ed. d'Heer Gouverneur ende desselffs aghtbaren raedt ende ten onzen overstaen als getuijgen. Alldus gedaen in Mattou desen $4^{\mathrm{e}}$ Maij 1659 en was dierwegens ijcler met zijn gewoonlijck merck offte naem geteijckent, te weten bij D'oulingh' Lavaos, capiteijn van Taijvorangh, Ourine Hamell claer op Lipangh, Aurij Varo Spou Tava, Jacob Tarrissan Veirong Vara, Vokingh Tdoukor Vara, Lie Tsaro en Taleij Tdomos, capiteijn van Mattouw. Ter zijden stondt Abhams. Daniel Hendricksz, ${ }^{1}$ ) J. Horstman ${ }^{2}$ ) en Cornelis Jacobsz.

\section{ATJEH.}

\section{Juni 1659. ${ }^{3}$ )}

Ook na het verdrag van 7 December 1655 (zie hiervoor, $n^{0}$. CCXVI), dat de moeilijkheden omtrent Perak had getracht ter zijde te stellen, wilde het tusschen de O. I. C. en Atjeh niet vlotten. Trouwens, Perak was het niet alleen, dat reden tot verwikkelingen gaf. Ook op Sumatra's Westkust begon steeds meer de botsing tusschen Atjeh en de onzen op den voorgrond te komen, waarschijnlijk ook ten gevolge van den naijver der Engelschen op onzen handel daar. Verder was de zucht der Nederlanders

1) Grothe, Archief, IV, bldz. 232, v.

2) Grothe, t.a.p., bldz. 198.

3) Uit hẹt Contractboek. 